\title{
Expect the Exceptional
}

\author{
${ }^{1}$ Gargi S Sarode, ${ }^{2}$ Sachin C Sarode, ${ }^{3}$ Shankargouda Patil
}

\section{ABSTRACT}

A 20-year-old female reported with chief complaint of pain in the left mandibular third molar region. Intraoral examination revealed inflamed area was notice near the retromolar area. Radiological examination showed impacted left third molar with pericoronal radiolucency of about $2.5 \mathrm{~mm}$. Surgically, a very small cystic cavity was noticed surrounding the crown of the impacted third molar. Histopathological examination revealed a small cystic space lined by epithelium of two to three cell layers thick. The final diagnosis of dentigerous cyst was made. Thus, odontogenic lesion may be found in radiographically normal follicular space.

Keywords: Odontogenic cysts, Dentigerous cyst, Impacted tooth.

How to cite this article: Sarode GS, Sarode SC, Patil S. Expect the Exceptional. World J Dent 2014;5(3):196-197.

\section{Source of support: Nil}

\section{Conflict of interest: None}

\section{INTRODUCTION}

Dentigerous cyst is the second most common odontogenic cyst encountered by general dentists. It is formed due to accumulation of fluid between the layers of reduced enamel epithelium (REE) or between REE and tooth surface. It is always associated with impacted tooth and the most common tooth is mandibular third molar. A dentigerous cyst may be discovered as an incidental radiographic finding or by examination of a clinical expansion. But we came across a dentigerous cyst of dental follicle of an impacted third molar without clinical and radiological evidence of any follicular lesion.

Dental follicle is the remnant of the tissues that participated in the odontogenesis and remained circumjacent

\footnotetext{
${ }^{1-3}$ Associate Professor

1,2Department of Oral Pathology and Microbiology, Dr DY Patil Dental College and Hospital, Dr DY Patil Vidyapeeth, Pune Maharashtra, India

${ }^{3}$ Department of Oral Pathology and Microbiology, Faculty of Dentistry, MS Ramaiah University of Applied Sciences Bengaluru, Karnataka, India
}

Corresponding Author: Sachin C Sarode, Associate Professor Department of Oral Pathology and Microbiology, Dr DY Patil Dental College and Hospital, DrDY Patil Vidyapeeth, Maheshnagar, Pimpri Pune-18, Maharashtra, India, Phone: +91-9922491465, e-mail: drsachinsarode@gmail.com to the crown of the tooth whose normal eruption has not occurred. The potential transformation of dental follicle of unerupted teeth into cystic or neoplastic ones is related to the constituent structures of the follicle, in particular, the reduced enamel epithelium and remnants of dental lamina located in its connective tissue wall. The radiolucent area (follicular tissue) around these teeth has a potential to develop pathological conditions. However, there has been no internationally accepted consensus in the dental literature to date on clinical criteria to differentiate between normal and pathological conditions of follicular tissue based on the radiographic features around impacted tooth. ${ }^{1}$ Previous studies suggest that normal pericoronal radiolucency is in the range of 2 to $3 \mathrm{~mm}$, although there is limited scientific data attesting the validity of this assumption. ${ }^{2}$ Several recent studies have demonstrated considerable pathosis in cases with clinically normal radiolucency. ${ }^{1,3-5}$

In the present case, a 20-year-old female reported with chief complaint of pain in the left mandibular third molar region. On intraoral examination, inflamed area was notice near the retromolar area. Panoramic radiograph revealed mesioangularly impacted left third molar with pericoronal radiolucency of about $2.5 \mathrm{~mm}$ (Fig. 1). During extraction of third molar, a very small cystic cavity was noticed surrounding the crown of the impacted third molar. The tooth was extracted along with soft-tissue which was attached to the cementoenamel junction and sent for histopathological examination (Fig. 2). Histopathological examination revealed a small cystic space lined by epithelium of two to three cell layers thick resembling REE (Fig. 3). The final

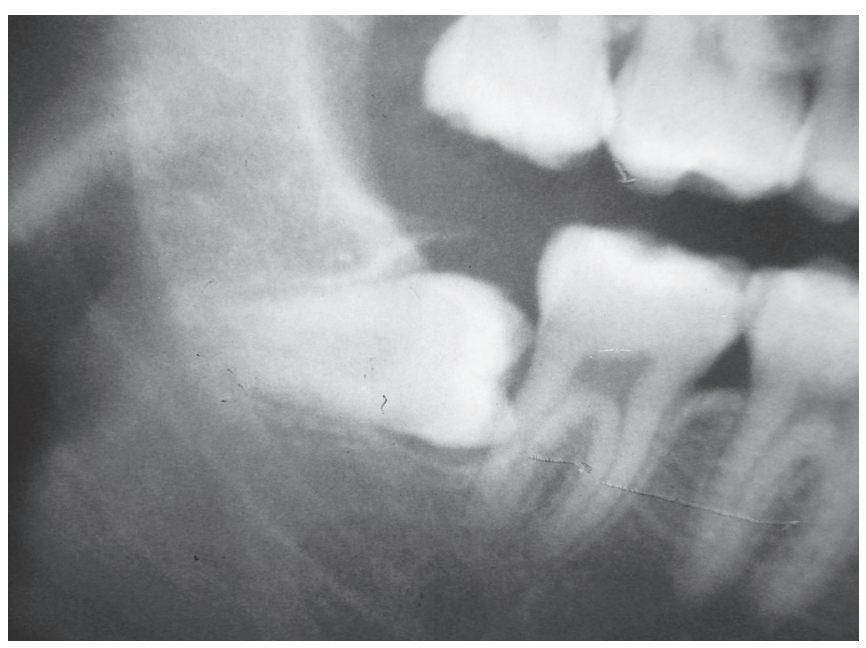

Fig. 1: Impacted mandibular third molar with radiolucent follicular space 

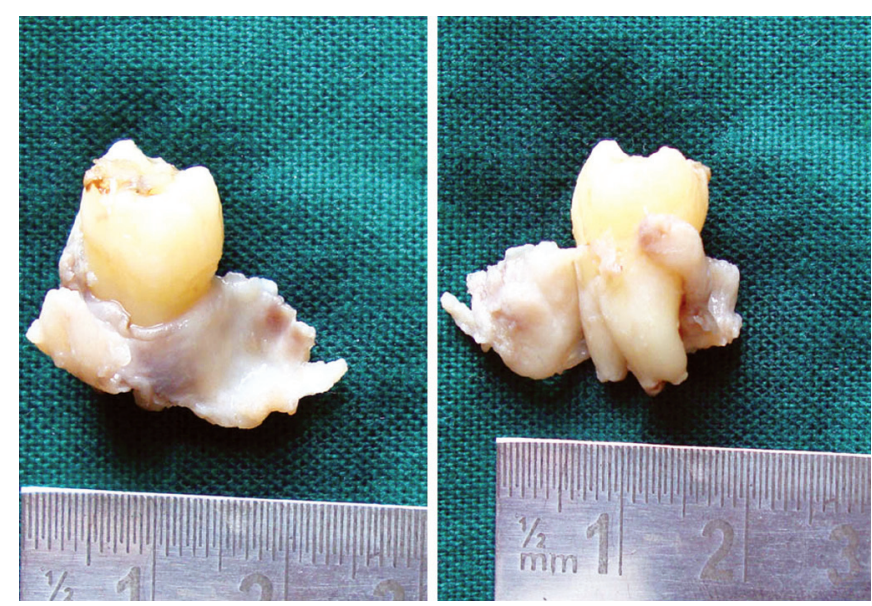

Fig. 2: Gross pathology showing soft-tissue attach to cementoenamel junction of tooth

diagnosis of dentigerous cyst was made. We believe that this could be the initial presentation of the early stages of developing dentigerous cyst.

Thus, it is very important to remember that the radiographic appearance may not be a reliable indicator of the presence or absence of the disease. Odontogenic lesion may be found in radiographically normal follicular space and many enlarged follicles are radiographically normal.

\section{REFERENCES}

1. Chu FC, Li TK, Lui VK, Newsome PR, Chow RL, Cheung LK. Prevalence of impacted teeth and associated pathologies: a

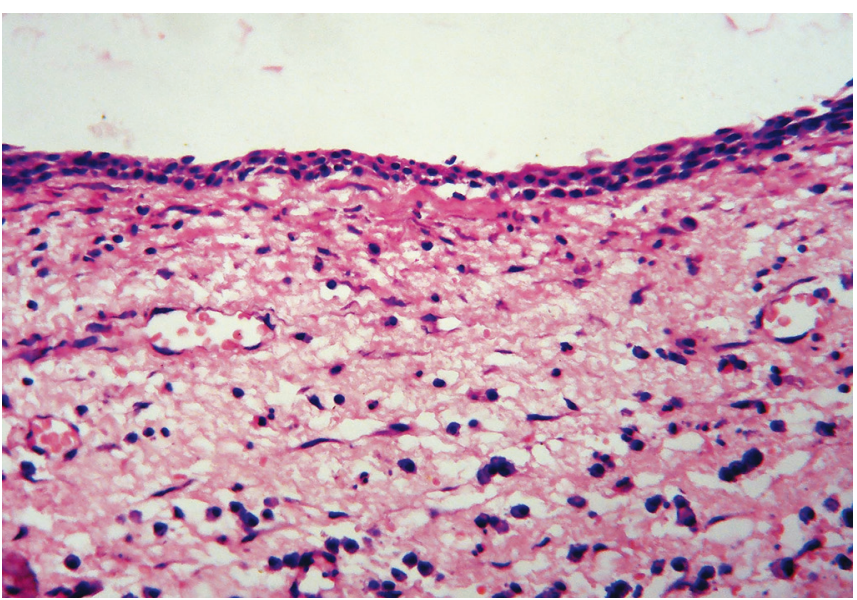

Fig. 3: Photomicrograph showing characteristic two to three cell layer thick lining of dentigerous cyst (HE stain; $40 \times$ magnification)

radiographic study of Chinese population. Hong Kong Med J 2003;9(3):158-163.

2. Peterson LJ, Eliis E, Hupp JR, Tucker MR. Editors contemporary oral and maxillofacial surgery. 4th ed. St. Louis: Mosby; 2003.

3. Baykul T, Saglam AA, Aydin U, Basak K. Incidence of cystic changes in radiographically normal third molar impactions. $\mathrm{Br}$ J Oral Maxillofac Surg 1999;37(4):259-260.

4. Adelsperger J, Campbell JH, Coates DB, Summerlin DJ, Tomich CE. Early soft-tissue pathosis associated with third molars without pericoronal radiolucency. Oral Surg Oral Med Oral Pathol Oral Radiol Endod 2000;89(4):402-406.

5. Raprasitkul S. Pathologic changes in the pericoronal soft tissue of unerupted third molars. Quintessence Int 2001;32(8):633-638. 